Int. J. Morphol.,

26(1):103-112, 2008.

\title{
Mesotelioma Invasivo de un Canino: Citología, Clínica y Hallazgos Patológicos
}

\author{
Invasive Mesothelioma of Canine: Cytology, Clinical and Pathology's Findings
}

*Julieta Ochoa Amaya \& ** Gilma Hernández Arevalo

\begin{abstract}
OCHOA, A. J. \& HERNANDEZ, A. G. Mesotelioma invasivo de un canino: Citología, clínica y hallazgos patológicos. Int. J. Morphol., 26(1):103-112, 2008.

RESUMEN: Este reporte describe los hallazgos macro y microscópicos de un mesotelioma invasivo epitelial y mesotelioma bifásico (mixto) maligno en un canino macho de 8 años de edad, raza Pit Bull, que llegó a la Clínica Veterinaria de la Escuela de Medicina Veterinaria y Zootecnia de la Facultad de Ciencias Agropecuarias y Recursos Naturales de la Universidad de los Llanos, cuyo motivo de consulta fue aumento del tamaño del abdomen, ascitis, anorexia, pérdida de peso, depresión, dificultad respiratoria y vómito. Según lo reportado por el propietario, el animal había recibido tratamiento para una falla renal que venía presentando meses atrás. Por el pobre pronóstico y orden del propietario, el animal fue eutanasiado y se remitió para necropsia al Laboratorio de Histopatología Veterinaria de la Universidad, siendo realizada la examinación post mortem. A la necropsia, se halló un tumor que comprometió el pericardio con dos neoplasias ulceradas, el mediastino y peritoneo, con numerosas multifocales o, a menudo, confluentes masas neoplásicas blanquecinas, las cuales estaban esparcidas a través del omento y superficies serosas de los órganos de la cavidad abdominal, como en el riñón derecho, páncreas e igualmente dos masas bilobuladas de color rojo de 1 x 1,5 cm en el tejido subcutáneo de la región inguinal, por extensión directa a través del peritoneo, implantación e invasión del tejido subyacente. Por histopatología, se diagnosticó un mesotelioma invasivo epitelial y mesotelioma bifásico maligno, con metástasis a riñón y páncreas, en los que se encontraron células mesoteliales neoplásicas con figuras mitóticas frecuentes, binucleación e invasión de tejidos submesoteliales infiltrados. En hemograma realizado previo a la necropsia, se encontró en el frotis sanguíneo, células blásticas y núcleos desnudos, hallazgos compatibles con una leucemia mielomonocítica.
\end{abstract}

PALABRAS CLAVE: Canino; Mesotelioma; Leucemia mielomonocítica.

\section{INTRODUCCIÓN}

Los tumores mesoteliales son neoplasias localizadas, multifocales o difusas que se originan de la línea mesotelial de las cavidades celómicas, pleura, peritoneo, pericardio y, ocasionalmente, de la túnica vaginal testicular (Bacci et al., 2006; Kim et al., 2002; Wilson \& Dungworth, 2002; Reggeti et al., 2005; Morini et al., 2006; Yamate et al., 2007). El mesotelioma maligno (MM) es una neoplasia fatal que se ha reportado en humanos, y en muchas especies animales incluido caninos, equinos, bovinos, felinos y ratas (Reggeti et al.; Bacci et al.; Yamate et al.) en la que la pleura representa el sitio más común de presentación seguido por el peritoneo, es extremadamente raro en pericardio y túnica vaginalis testis (Abbas et al., 2006), aunque estudios realizados en efusiones pericárdicas de caninos en la Universidad de Wisconsin revelaron que son más frecuentes de lo que se reportan, (Machida et al., 2004).
El mesotelioma en todas las especies, está asociado a la exposición a asbesto, virus simiam 40 (SV 40) y, en algunas ocasiones, a óxido de aluminio (Reggeti et al.). Experimentalmente se han expuesto perros a polvo de asbesto, los cuales han producido adenocarcinoma pulmonar y mesoteliomas extensos. En forma natural fueron encontrados mesoteliomas fibrosos intersticiales pulmonares y placas fibróticas pleurales en perros expuestos al asbesto (Head et al., 2003); igualmente, han sido inducidos mesoteliomas mediante exposición intratraqueal a fibras de asbesto o por humo de cigarrillo, en primates no humanos y roedores (Borrow et al., 1973; Harbinson \& Godleski, 1983; Kim et al.); en ratas y hamsters ha sido inducido mesotelioma por inhalación o inyección de asbesto, fibras de vidrio y óxido de aluminio (Kannerstein \& Churg, 1980; Reggeti et al.); de igual manera en ratas el mesotelioma también fue inducido

\footnotetext{
* Docente de Patología Veterinaria - Universidad de los Llanos - Villavicencio, Meta. M.V.Z. MsC. Patología Experimental y comparada-USP/

** Profesora de Laboratorio Clínico - Universidad de los Llanos- Villavicencio, Meta. M.V.Z. MsC. microbiología - Universidad Javeriana/ Colombia.
} 
por inyecciones intracavitarias del virus simiam 40 (SV40) (Mutsaers, 2004; Reggeti et al.).

Los mesoteliomas benignos y malignos tienen una estructura básica similar, por lo cual, en algunos casos, puede ser difícil establecer un diagnóstico. Un claro pronóstico de malignidad es la presencia de células tumorales en vasos linfoides a una distancia considerable desde la superficie profunda de los tumores y con metástasis a nódulos linfoides (Peters et al., 2002). Parece que los vasos sanguíneos y linfáticos del pericardio son los blancos primarios de la enfermedad y el daño de los vasos es la fuente de la efusión (Berg et al., 1984; Aronsohn \& Carpenter, 1999; Machida et al.). Se asume que esas células mesoteliales descamadas entran a los vasos linfáticos submesoteliales a través de los poros intercelulares de la serosa y son luego transportados por los nódulos linfáticos que los drenan (Suárez \& Izquierdo, 1998; Parkash et al., 1999; Peters et al.). Por otro lado, el microambiente hematopoyético de la médula ósea depende de un estímulo multidireccional, donde la respuesta celular induce la producción de factores solubles como citoquinas, factores neurotrópicos y neuropéptidos que incluyen la sustancia $P$, sugiriendo que la función y posiblemente las propiedades de las células madre hematopoyéticas, puedan ser influenciadas por el sistema nervioso (Nowicki et al., 2007). El papel de la sustancia P (SP) en la hematopoyesis está bien establecida; sin embargo, también es importante en la transformación de la médula ósea, direccionando el desarrollo de leucemia aguda en niños y también metástasis a médula ósea de tumores sólidos, particularmente neuroblastoma y cáncer de pecho (Nowicki et al.).

Kobayashi et al., en 1994, encontraron en un gato de 17 años de edad un mesotelioma abdominal maligno, asociado a leucemia de células de Mast. Las neoplasias estaban localizadas en la periferia del bazo, páncreas y estómago con metástasis a pulmón, nódulos linfáticos del mediastino y conductos linfáticos; ellos consideraron que los defectos microcirculatorios causados por la leucemia pudieron, en parte, haber sido responsables de la metástasis a distancia.

Las masas sólidas de células del tumor muestran una marcada anisocitosis y anisocariosis, siendo éstas más comunes en los tumores malignos. Las mitosis pueden ser vistas más frecuentemente, pero algunos mesoteliomas metastásicos tienen pocas figuras mitóticas. Pueden encontrarse áreas de necrosis en los mesoteliomas malignos y estar bajo mineralización distrófica, la cual puede diferenciarse de metaplasia ósea y formación de cartílago, esto especialmente en ganado, en el cual el mesotelioma es una neoplasia a menudo congénita (Head et al.; Bacci et al.; López, 2001). Entre los mesoteliomas malignos existe una varie- dad predominantemente epitelioide maligna, el cual es un tumor compuesto de células mesoteliales epitelioides con varios grados de anaplasia y crecimiento dentro del tejido fundamental, vasos linfáticos y sanguíneos. Otro tipo de mesotelioma es el predominantemente fibroso maligno o de células spindle, siendo éste un tumor mesotelial maligno, semejando un fibrosarcoma y mostrando infiltración dentro del tejido conectivo adyacente. El tercer tipo de mesotelioma maligno es el bifásico o mixto, el cual es un tumor maligno con algunas áreas de carcinoma y otras áreas con apariencia sarcomatoide (Bacci et al.; Head et al.). En los perros, el patrón histológico del mesotelioma tiene características bifásicas o epitelioides comprometiendo la pleura, peritoneo, pericardio o túnica vaginal en un orden de frecuencia decreciente de presentación (Head et al.).

La leucemia mielomonocítica es una condición poco frecuente, caracterizada por proliferación de células blásticas, tanto de neutrófilos como de la línea celular monocítica (Bernard et al., 2002, Valli et al., 2002), donde la proliferación y diferenciación anormal de presursores monocíticos y mieloides dependen del factor estimulante de colonias macrófago-granulocítico (GM-CSF). Las leucemias mieloides agudas o crónicas son altamente letales y malignas (Reiko et al., 1993; Bernard et al.), y en un caso reportado por Tarrant et al. (2001), encontraron que una leucemia mieloide crónica en un canino, se transformó en leucemia aguda después del tratamiento. Leucemias monocíticas son menos frecuentes en animales y los principalmente afectados son caninos, felinos adultos y ocasionalmente equinos (Valli et al.). Los animales generalmente presentan una buena condición corporal con anemia moderada no regenerativa y conteo de células blancas en el rango de 50.000/ml, de los cuales las formas monocíticas predominan. En la leucemia mielomonocítica, los blastos de ambos tipos celulares están presentes en la sangre periférica, y la médula es caracterizada por marcada reducción en la producción eritroide y pérdida de las reservas granulocíticas medulares. Al menos el $20 \%$ de las células medulares son del tipo blasto (Valli et al.). Los signos clínicos reflejan anemia, leucopenia y trombocitopenia (Nowicki et al.).

\section{HISTORIA CLINICA}

A la Clínica Veterinaria de la Escuela de Medicina Veterinaria y Zootecnia de la Facultad de Ciencias Agropecuarias y Recursos Naturales de la Universidad de los Llanos, llegó un canino macho de 8 años de edad raza Pit Bull, cuyo motivo de consulta fue aumento del tamaño del abdomen, ascitis, anorexia, pérdida de peso, depresión, dificultad respiratoria y vómito. Según lo reportado por el 
propietario, el animal había recibido tratamiento para una falla renal que venía presentando meses atrás y solicitó la eutanasia. Debido a esto, se realizó un examen clínico encontrándose los siguientes hallazgos anormales: pelo hirsuto, opaco, epífora bilateral, tamaño aumentado del abdomen, ascitis, mucosas pálidas e ictéricas, ausencia de dientes incisivos y placa bacteriana en los demás dientes, se tomó una muestra de sangre. Luego fue eutanasiado el animal aplicándose $5 \mathrm{ml}$ de Eutanex y se remitió a patología para la correspondiente necropsia.

\section{EXAMEN POSTMORTEM}

Hallazgos macroscópicos. Los principales hallazgos a la inspección externa fueron: estado de carnes disminuido, mucosas ictéricas, epífora bilateral, pelaje áspero y opaco, cavidad oral sin incisivos y con placa bacteriana en las demás piezas dentarias, se presentaba un aumento en el tamaño del abdomen, zonas alopécicas con hiperqueratosis. Los hallazgos macroscópicos principales fueron, en la cavidad pleural: agrandamiento de los nódulos linfáticos traqueobronquiales y mediastínicos, hemopericardio (Fig. 1A), pul-
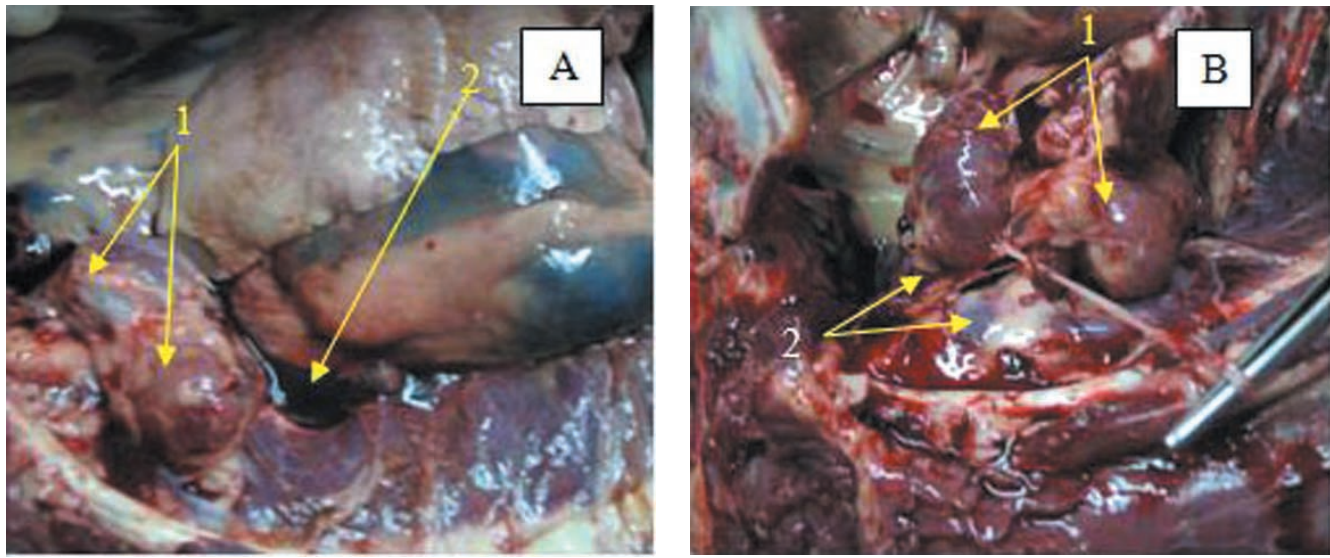

Fig. 1. A) 1. Presencia de dos neoplasias con tres y cuatro lóbulos cada una, ubicadas craneal a la base del corazón y con adherencias a la pleura, 2. Hemopericardio. B) 1. Masas neoplásicas, proximales al corazón; 2. Tejido de adherencia a la pleura.
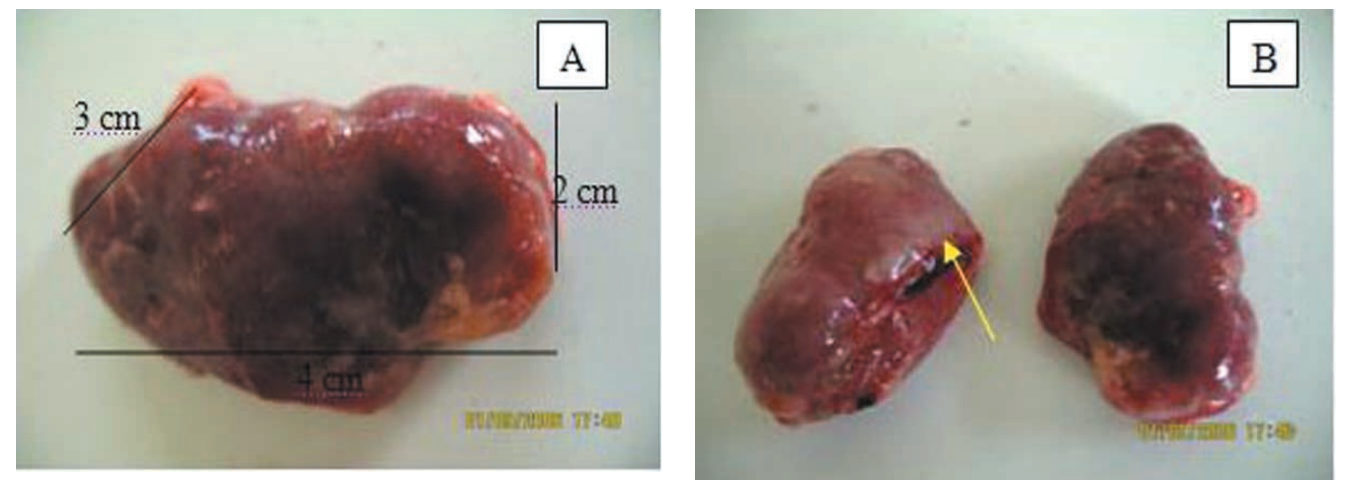

Fig. 2. A) Disección de una de las neoplasias encontradas proximales a la base del corazón, B) Corte longitudinal de una de las neoplasias, donde se puede observar una cavidad con líquido serosanguinolento. mones y pleuras pálidos, dos neoplasias de color rojo con tres y cuatro lóbulos cada una, ubicadas craneal a la base del corazón y con adherencia a la pleura (Figs. 1A, 1B, 2A, 2B). Dos neoplasias ulceradas adheridas internamente a la pleura pericárdica (Figs. 3A y 3B) notándose la adherencia a la pared de la aorta de otra neoplasia ubicada en la base de la aorta (Fig. 4A), de consistencia dura, lobulada en su base, color blanco, en su superficie hemorragias petequiales y equimóticas. Cuando se expuso la pleura pericárdica, se encontraron otras masas neoplásicas de color rojo, próximas a los vasos coronarios, ulceración de algunas de las neoplasias, posible causa de hemopericardio (Fig. 4B). La cavidad abdominal contenía una gran cantidad de fluido serosanguinolento. Numerosas masas neoplásicas blanquecinas esparcidas a través del omento y superficies serosas de los órganos de la cavidad abdominal, dispuestas cerca a los vasos sanguíneos del mesenterio, así como en el riñón derecho que estaba aumentado de tamaño debido a la presencia de masa blanquecina en el polo craneal de $2.5 \mathrm{~cm} \mathrm{x}$ $3.5 \mathrm{~cm}$ (Fig. 5A), esplenomegalia (Fig. 5B), hígado congestionado y hemorrágico con bordes redondeados e, igualmente, dos masas bilobuladas de color rojo de 1 X $1,5 \mathrm{~cm}$ en el tejido subcutáneo de la región inguinal por extensión directa a través del peritoneo, implantación e invasión directa del tejido subyacente (Fig. 6).

Hallazgos microscópicos. Después de realizada la necropsia, se tomaron muestras para histopatología, en formalina buferada al 10 $\%$, de las masas neoplásicas encontradas, las cuales fueron rutinariamente procesadas y coloreadas con hematoxilina y eosina (HE) para examinación por microscopía de luz.

Se procesaron varios cortes de tejido. Los principales hallazgos en la neoplasia encontrada en la cavidad torácica, incluyendo 

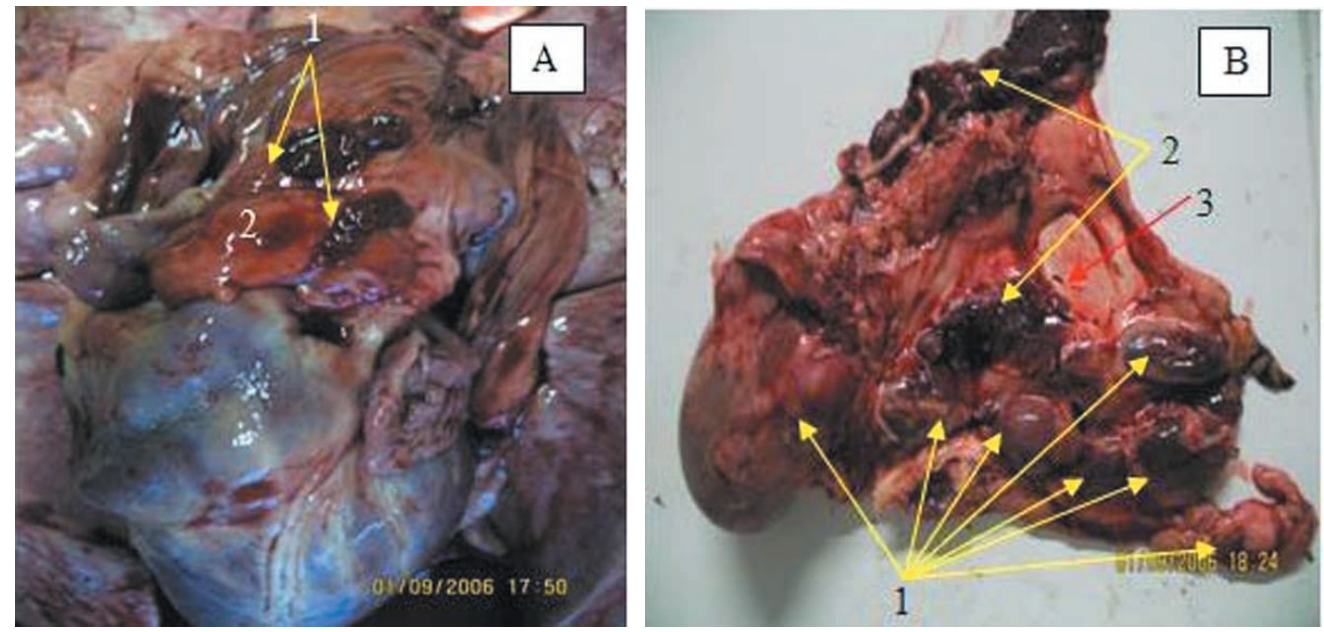

saco pericardio y las masas encontradas en base de la aorta corresponden a un mesotelioma bifásico, donde ningún tipo celular predomina (Figs. 7A y 7B), con algunas áreas carcinomatosas y otras áreas de apariencia sarcomatoide, compuesto por células mesoteliales epitelioides, células spindle de origen sarcomatoso, que semejan fibroblastos. El mesotelioma

Fig. 3. A) 1. Neoplasias ulceradas adheridas internamente a la pleura pericárdica; 2. Neoplasia en la base de la aorta de consistencia dura lobulada en su base, de color blanco. B) Exposición de la pleura pericárdica. 1. Masas neoplásicas próximas a los vasos coronarios y la aorta. 2. Ulceración de algunas neoplasias, posible causa de hemopericardio, 3. Pared de la aorta, nótese la adherencia al vaso sanguíneo.
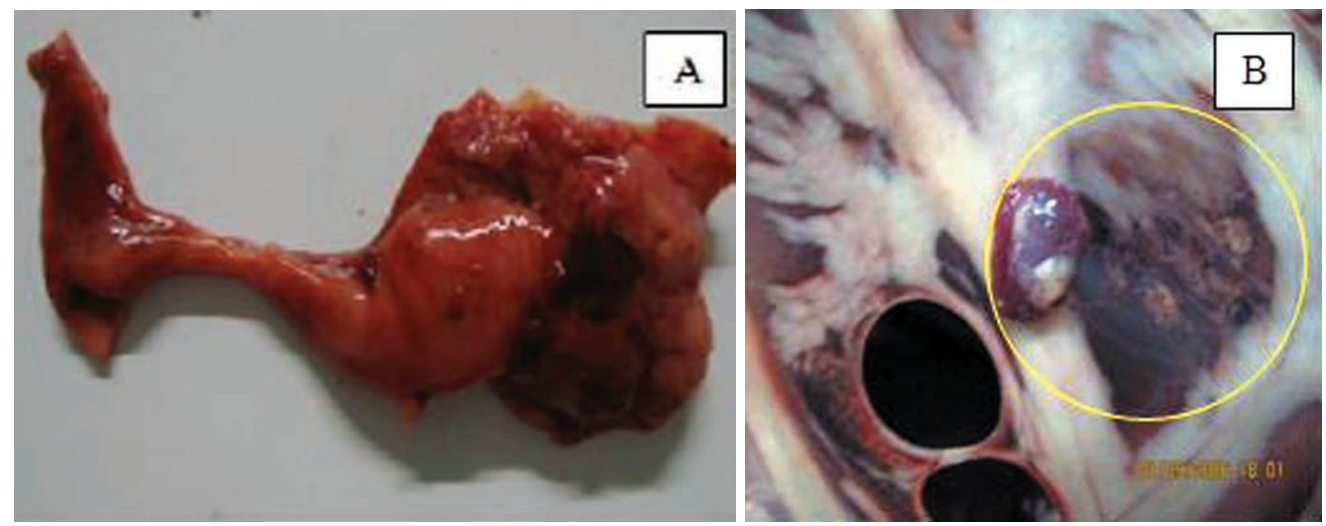

Fig. 4. A) Neoplasia de color blanquecino, ubicada en la base de la aorta, en su superficie tiene petequias y manchas equimóticas, su base es de forma lobulada. B) Masas neoplásicas adheridas al mesenterio, dispuestas proximal a los vasos sanguíneos.
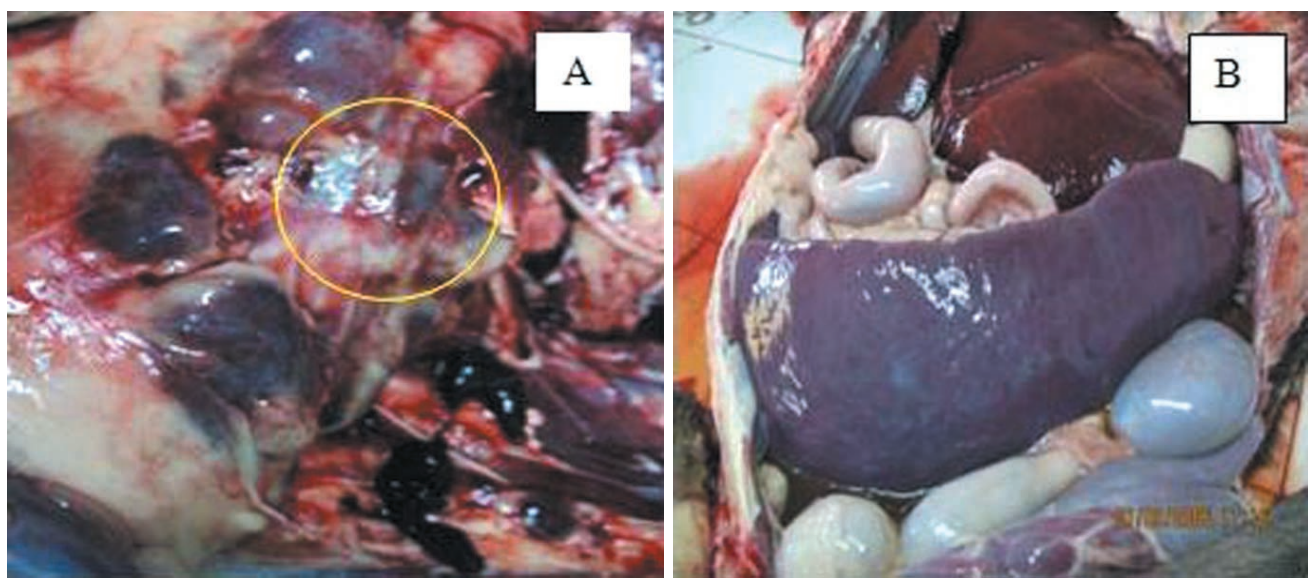

Fig. 5. A) Riñón aumentado de tamaño y pálido. Congestión medular. Presencia de masa blanquecina en el polo craneal de riñón derecho $(2,5 \mathrm{~cm}$ x $3,5 \mathrm{~cm})$. B) Bazo ocupando gran parte de la cavidad abdominal comprimiendo y desplazando las vísceras hacia el tórax. Abundante líquido en cavidad abdominal (350 ml). solamente por células mesoteliales epitelioides con variante grado de anaplasia y un alto número de figuras mitóticas por campo, con un aumento total de $40 x$ (Fig. 7 C).

Las células neoplásicas mesoteliales con forma cuboidal, redondas u ovaladas, núcleo vesiculado con prominente nucléolo y una pequeña a moderada cantidad de citoplasma, formando agrupaciones de células con forma de roseta y mórulas, también pueden apreciarse células spindle con núcleo alargado y de color oscuro y áreas de desmoplasia (Fig. 7 D).

Dando un estímulo apropiado, el mesotelio es activado y ocurre una hiperplasia o una forma de neoplasia, donde hay proliferación y transformación de las 


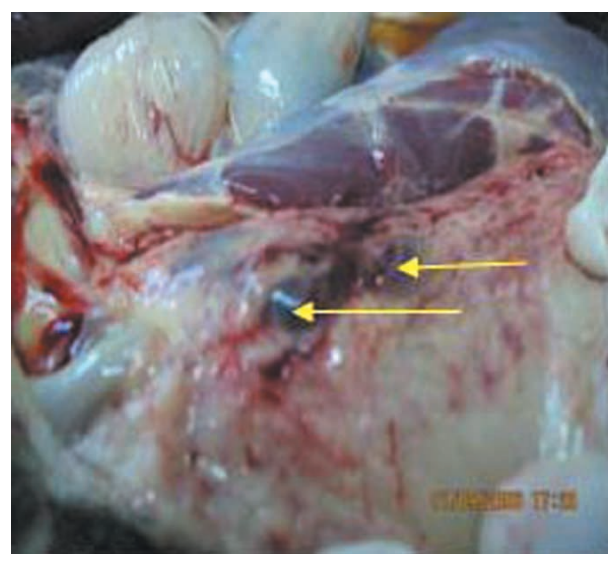

Fig. 6. Presencia de dos neoplasias bilobuladas de $1 \mathrm{~cm} \times 1,5 \mathrm{~cm}$ en el tejido graso subcutáneo de la región inguinal.
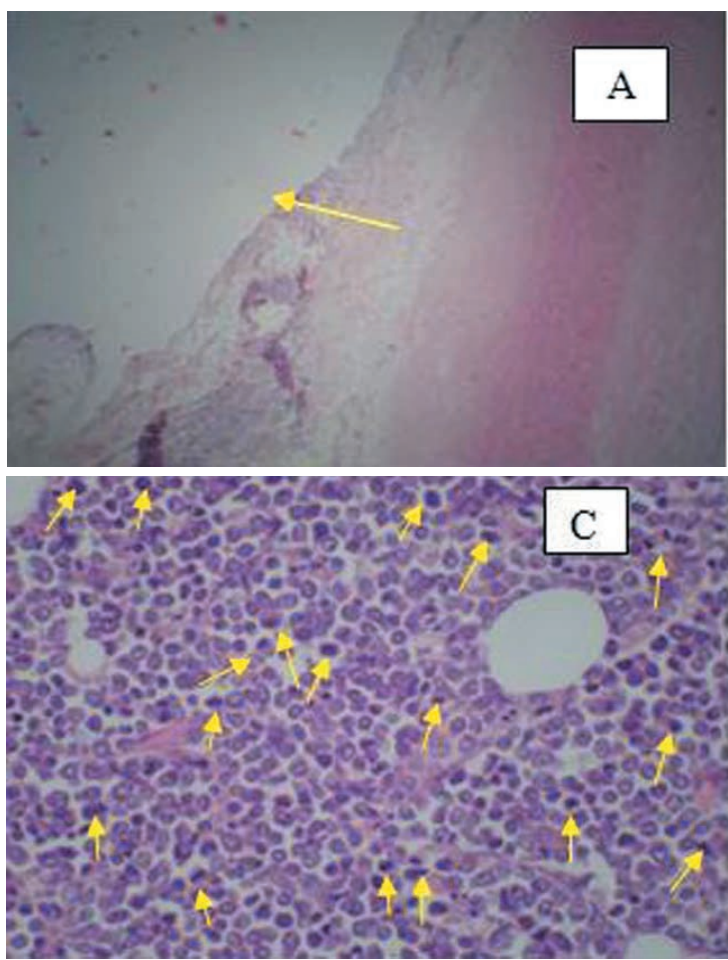

En el corte de páncreas puede apreciarse telangiectasia con células mesoteliales embolizadas provenientes del mesotelioma encontrado en el peritoneo (Fig. 9 A).Un acercamiento del infiltrado neoplásico permite visualizar las células mesoteliales metastásicas con pocas figuras mitóticas (Fig. 9 B), esas células pueden ser únicas o presentarse en grupos de 5 a 50, formando rosetas y mórulas (Fig. 9 B).

En el mesotelioma epitelioide, las mitosis pueden ser vistas más frecuentemente (Fig. 9 C), las células mesoteliales epitelioides presentan anisocitosis y anisocariosis. En el mesotelioma bifásico puede, observarse las células mesoteliales a todo lo largo con micro vellosidades sobre su


Fig. 7. Mesotelioma bifásico, HE, 10X y 40X, respectivamente (A y B). Proyección de células mesoteliales neoplásicas como lo indica la flecha. Células spindle de origen sarcomatoso. Células mesoteliales. Mesotelioma epiteliode. C) 16 figuras mitóticas por campo con aumento de 40X.*Crecimiento de células neoplásicas en forma de roseta. ** Células spindle con núcleo alargado y de color oscuro. *** Desmoplasia. Áreas de color rosado que corresponden a colágeno, aumento de 40X.

células mesoteliales al tipo pavimentoso (Fig. 8A) y células mesoteliales con crecimiento en forma papilar (Fig. 8B), esas células son intermediarias en tamaño de citoplasma y núcleo, forma y número de nucléolo. La anisocitosis y anisocariosis son menos marcadas que en un mesotelioma pero se observan las células binucleadas (Fig. 8A). Un mesotelioma puede estimular la hiperplasia celular mesotelial en áreas no neoplásicas, como puede apreciarse en este reporte de caso. superficie, cara basal y siempre en los espacios intracitoplasmáticos. Algunas veces, esas microvellosidades con forma de raíces (Fig. 9 D) tienen un radio longitud diámetro en relación 12 a 1 , pero son variables en número y distribución. Algunas de esas células pueden soltarse dentro del fluido de la cavidad serosa.

En el riñón puede observarse daño glomerular, glomeruloesclerosis e infiltrado periglomerular de células 

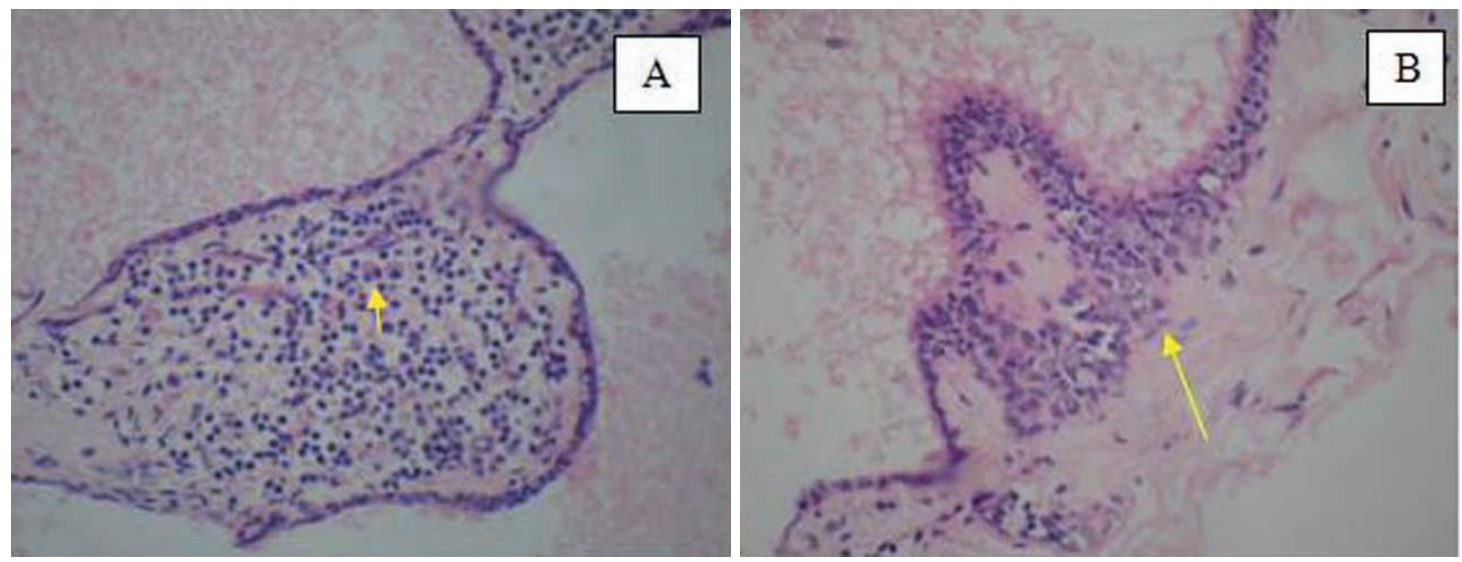

Fig. 8. A) Mesotelio activado, HE, 10X, con células mesoteliales reactivas cuboides, núcleo grande y poco citoplasma. Presencia de células binucleadas. B) Mesotelio activado, HE, 40X. Crecimiento de células mesoteliales que se disponen en arquitectura papilar, delimitadas por una banda de células spindle con núcleo alargado de origen sarcomatoide.
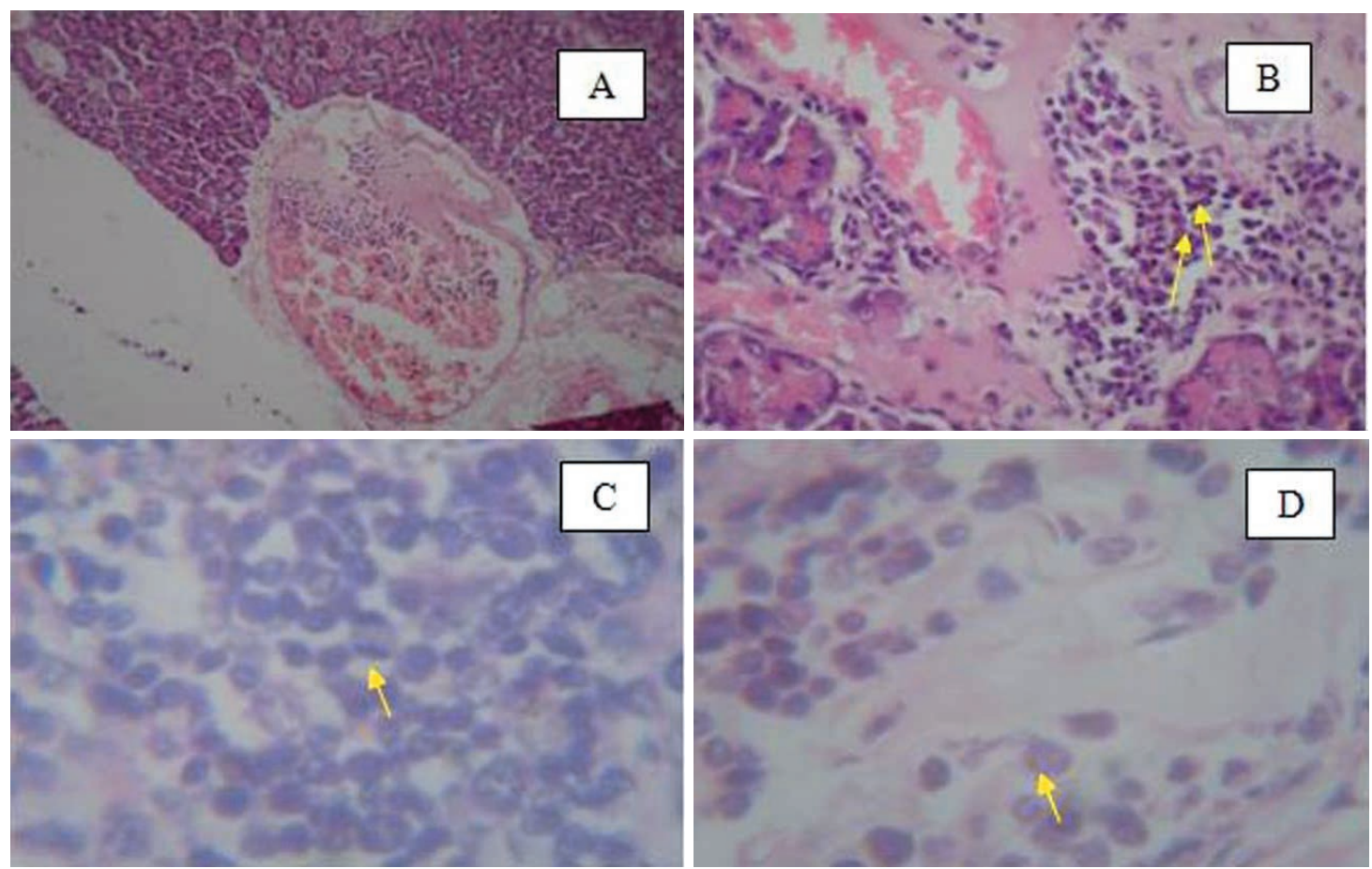

Fig. 9. Metástasis del mesotelioma a páncreas, HE, 10X, 40X, respectivamente.A) Telangiectasia, trombosis y embolismo de células neoplásicas. B)Acercamiento al área de infiltración neoplásica con pleomorfismo celular, donde se observan cambios microcirculatorios y edema. C) Células mesoteliales, la flecha señala una figura de mitosis, variada anisocitosis y anisocariosis en todas ellas. D) Célula mesotelial con una microvellosidad en forma de coma.

mesoteliales neoplásicas y puede apreciarse daño tubular con degeneración tubular (Fig. 10A). En el riñón, se encuentra la pérdida de albúmina en la luz de los túbulos contorneados, donde se observan una coloración rosa pálida y hemorragias multifocales en la corteza renal. En otros campos de micropreparados se presentan zonas de necrosis tubular multifocales. Pueden apreciarse infiltrados de células mesoteliales, con disposición en forma de roseta (Fig. 10B).
Hemograma. Los resultados del único hemograma realizado al paciente, revelaron anemia no regenerativa con un valor del hematocrito de $25 \%$, hemoglobina de $9,2 \mathrm{~g} / \mathrm{dL}$ sin manifestación de reticulocitos ni macrocitos, pero sí con hipocromía. En cuanto a las células blancas se encontró un recuento total de $42.050 \mathrm{cel} / \mu \mathrm{L}$, lo que representa una leucocitosis moderada; sin embargo, llamó la atención que, al revisar el frotis, se encontró un promedio del $12 \%$ de núcleos desnudos y células en 

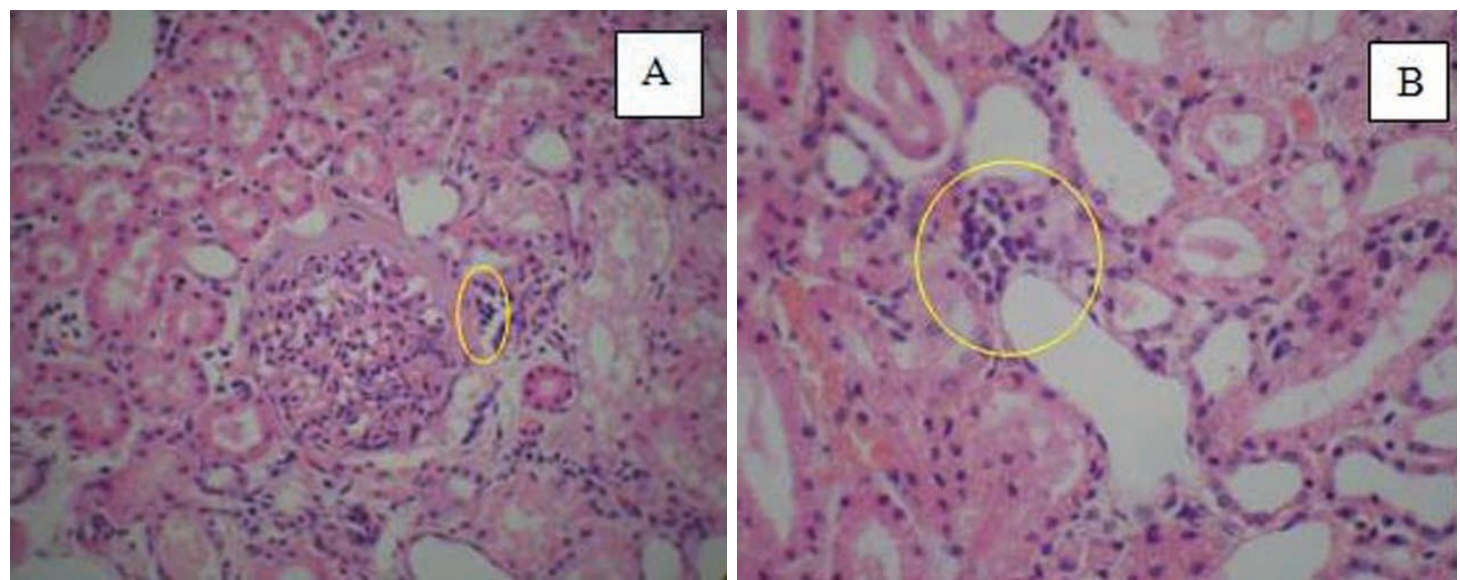

Fig. 10. Riñón, HE, 10X y 40X, respectivamente. A) Glomérulo con infiltrado periglomerular de células mesoteliales, glomérulo con esclerosis, degeneración vacuolar tubular. B) Células mesoteliales, variación en el tamaño de las células quese disponen en forma de roseta.

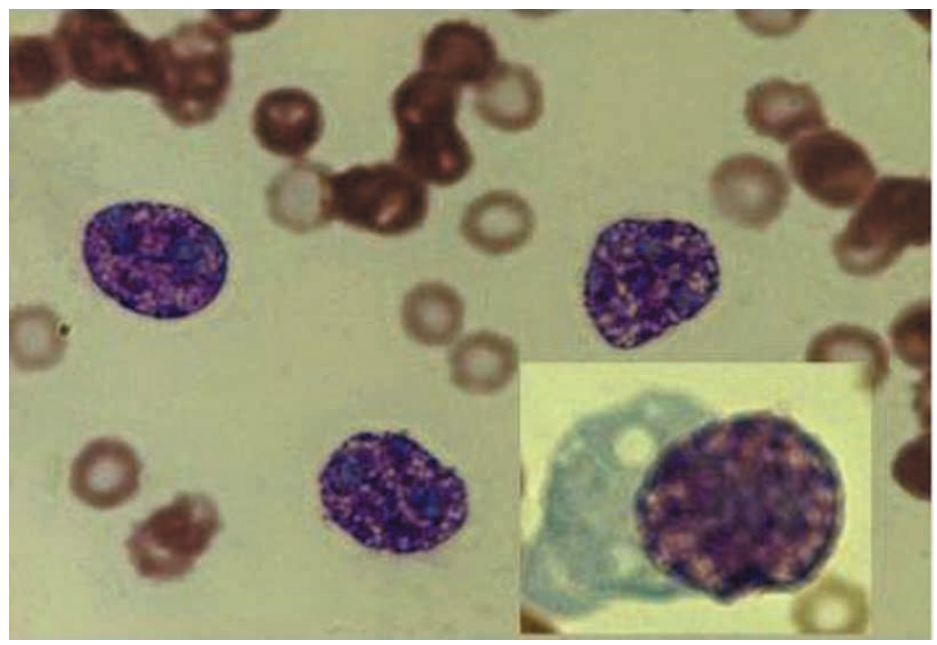

Fig. 11. Frotis sanguíneo. Se observan células que han perdido el citoplasma, En el recuadro se muestra una célula que está en proceso de separación núcleocitoplasma, razón por la cual resulta difícil la identificación de la línea celular. Coloración con Diff Quick, 100X.
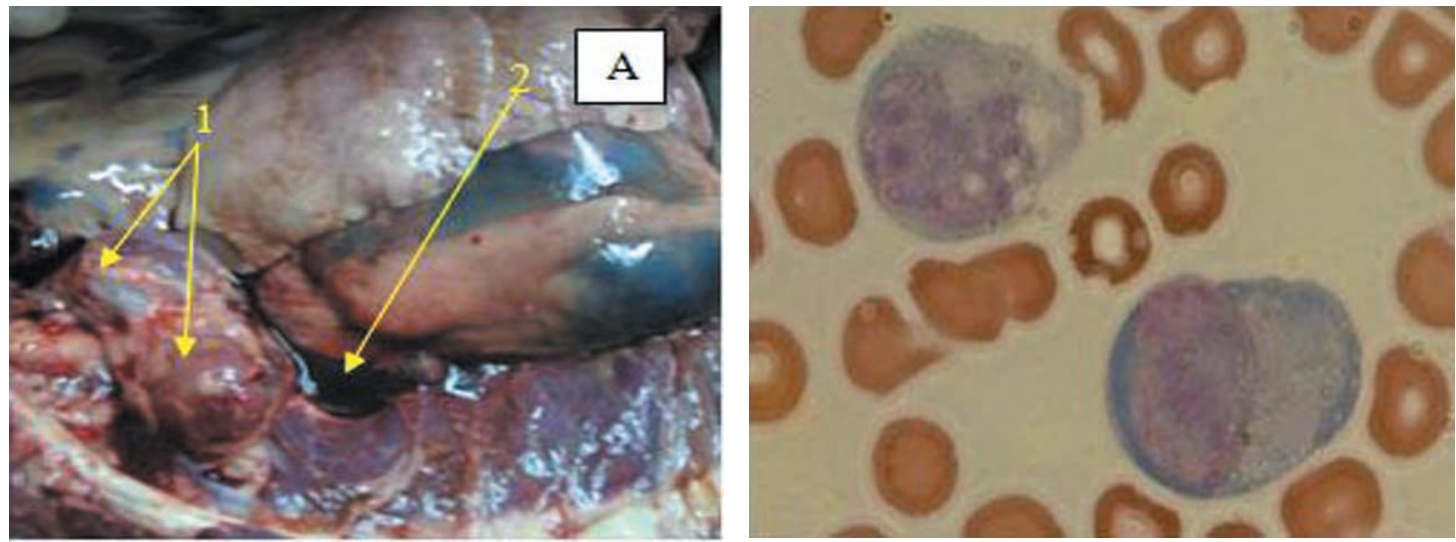

Fig. 12. Frotis sanguineo. A) Dos células de origen mieloide, con núcleo grande de color basófilo y citoplasma no muy amplio vacuolado. B) Células con núcleo reniforme y amplio citoplasma con menor grado de vacuolación. Coloración Diff Quick, 100X.

proceso de separación núcleo-citoplasma (Fig. 11) que no permite diferenciar claramente la línea celular involucrada para hacer el recuento diferencial de células blancas. Se encontraron además, células de origen mieloide, con núcleo grande basófilo y citoplasma no muy amplio, vacuolado de color azul, células con núcleo reniforme y amplio citoplasma de color azul correspondiente a la línea monocítica, lo que sugiere probablemente una leucemia mielomonocítica (Figs. 12A y 12B). 


\section{DISCUSIÓN}

El diagnóstico de necropsia para el canino en estudio, fue mesotelioma invasivo epitelial y mesotelioma bifásico (mixto) maligno, de acuerdo a los cambios macroscópicos y microscópicos encontrados. Conforme a lo descrito en la literatura, el animal de este estudio es viejo (8 años) y estuvo expuesto a asbesto, puesto que su propietario lo mantenía en un taller de remache de bandas de frenos, donde el ambiente es rico en asbesto y el animal los pudo respirar, ocasionándole este tipo de neoplasias. Glickman et al., 1983; Harbinson \& Godleski; Reggeti et al., han sugerido conformar la asociación de mesoteliomas en perros causadas por asbesto, con participación de otros carcinogénicos químicos o virales para el desarrollo de este mesotelioma maligno e invasivo en perros, por lo que implica la exposición a esta sustancia y la detección de fibras de asbesto en los pulmones.

Las lesiones observadas en el pericardio como, neoplasias en forma de placas rojas ulceradas, de las masas ubicadas craneal a la base del corazón con adherencia a la pleura, de la neoplasia lobulada blanquecina ubicada en la base de la aorta de consistencia dura, de las masas neoplásicas en forma de placas adheridas al mesenterio y de la masa blanquecina ubicada en el polo craneal del riñón, concuerdan con las descripciones macro reportadas para los mesoteliomas (Kim et al.; Reggeti et al.; Machida et al.; Bacci et al.; Meuton). Esas lesiones asumen una variedad de patrones histológicos (epitelioide y bifásico) y sus células constituyentes presentan características similares a las descritas microscópicamente para los mesoteliomas (Bacci et al.; Head et al.). Según los signos clínicos presentados en el animal, éste mostraba anorexia y depresión, disnea, distención abdominal, concordando con los hallazgos clínicos típicos (Dias Pereira et al., 2001; Jones et al., 1997; Meuton), efusión pericardial hemorrágica constituyéndose en un hemopericardio (Berg et al.; Aronsohn \& Carpenter; Machida et al.) el cual fue evidenciado en los hallazgos post mortem, de igual forma el paciente presentaba grandes cantidades de liquido en la cavidad abdominal, donde se encontraron varias neoplasias en forma de placa, esparcidas por el peritoneo, masas neoplásicas tanto en páncreas y riñón, región inguinal, base de la aorta, etc. Todas estas efusiones en pericardio como la ascitis son causadas por mesoteliomas (Machida et al.; Reggeti et al.; Kim et al.).

Microscópicamente, se evidenciaron, masas sólidas de células como las descritas por la literatura para mesotelioma epitelioide maligno, el cual es un tumor compuesto de células mesoteliales epitelioides con varios grados de anaplasia y crecimiento dentro del tejido fundamental, vasos linfáticos y sanguíneos. Generalmente, estos tumores muestran una marcada anisocitosis y anisocariosis, pleomorfismo bi y multinucleación, presentando más frecuentemente mitosis (Fig. 9A) (Bacci et al.; Head et al., 2003). Las células encontradas, adquieren estructuras papilares (Figs. 8A y 8B), se ubican en varias camadas y tienen vellosidades como raíces sobre su superficie (Fig. 9B), concordando con lo descrito por Head et $a l$, en donde las células mesoteliales tienen muchos filamentos perinucleares intermediarios, a todo lo largo, con micro vellosidades sobre su superficie, cara basal y siempre en los espacios intracito-plasmáticos. Algunas veces, esas microvellosidades con forma de raíces, tienen un radio longitud diámetro en relación 12 a 1, pero son variables en número y distribución.

El otro tipo de mesotelioma encontrado en el animal (Figs. 7A y 7B) es maligno bifásico o mixto, el cual presenta algunas áreas de carcinoma y otras áreas con apariencia sarcomatoide (Bacci et al.; Head et al.). En los perros, el patrón histológico del mesotelioma tiene características bifásicas o epitelioides, comprometiendo la pleura, peritoneo, pericardio o túnica vaginal en un orden de frecuencia decreciente de presentación (Head et al.) concordando con los hallazgos macro en este animal.

La entrada de las células mesoteliales dentro de los linfáticos puede ser facilitada por la distensión de los poros causada por la misma efusión o por lesiones e inflamación del tejido submesotelial (Suárez \& Izquierdo; Peters et al.). En el páncreas del animal se presentó telangiectasia con embolismo neoplásico, confirmando aún más las características de malignidad de este mesotelioma y su alta capacidad invasiva, concordando con que un claro pronóstico de malignidad es la presencia de células tumorales en vasos linfoides a una distancia considerable desde la superficie profunda de los tumores y con metástasis a nódulos linfoides (Suárez \& Izquierdo; Parkash et al.; Peters et al.). Los mesoteliomas metastáticos tienen pocas figuras mitóticas (Bacci et al.; Head et al.) lo que pudo evidenciarse tanto en páncreas como en riñón, donde las células presentaban un muy bajo nuúmero de figuras de mitosis. No siendo así en los sitios primarios de origen de la neoplasia de tipo epitelioide, donde se encontraron 16 figuras mitóticas por campo (40 x).

En el resultado del hemograma no hay evidencia clara de que la presencia de células neoplásicas sea consecuencia del mesotelioma, aunque los estados neoplásicos por lo general involucran varios factores, entre los que se considera la infiltración de médula ósea. Las células neoplásicas presentes pueden originarse directamente de los progenitores o pueden derivarse de células metastásicas diferentes de tumores sólidos (Nowicki et al., 2006). En este caso ,es posible que la sustancia $\mathrm{P}$ actuara no sólo como factor de crecimiento de las células tumorales, sino también como un agente regulador que aumenta la metástasis en médula ósea impidiendo así la 
hematopoyesis fisiológica (Nowicki et al.). Algunos reportes sugieren la posible asociación entre la exposición a asbesto y neoplasias linfoproliferativas, puesto que la estimulación antigénica crónica por el asbesto puede ser un factor predisponente (Efremidis et al., 1985).

Otra posibilidad es que el animal registrara una leucemia mieloide crónica, y al desencadenarse el mesotelioma se transformara rápidamente en leucemia aguda. Lupu et al. (1997) reportaron el hallazgo de una leucemia mieloide crónica en una paciente que, posteriormente, presentó signos de fase acelerada, crisis blastica y también una efusión hemorrágica pleural: Kobayashi et al. reprtaron la presentación de mesotelioma maligno abdominal como consecuencia de leucemia de células de mast en un felino, el cual presentó igualmente infiltración en páncreas, bazo y estómago.

El problema en este caso es el diagnóstico diferencial de la enfermedad hematológica y el síndrome neoplásico que apareció durante la evolución. En ambas patologías los análisis de laboratorio muestran una anemia, leucocitosis moderada y trombocitopenia. Sin embargo, lo que queda claro es que además del mesotelioma, el animal presentó leucemia posiblemente mielomonocítica (Figs. 12A y B).

\section{AGRADECIMIENTOS}

Agradecemos a la Clínica Veterinaria y al Laboratorio Clínico de la Universidad de los Llanos, al Sr. Carlos Isaquita Técnico del Laboratorio de Ictiopatología de la Universidad de los Llanos, al Laboratorio de Histopatología de la Universidad de los Llanos y a los estudiantes Dinora Daza, Paola Beltrán Rincón, Yuliana Zarabanda, Mónica Lesmes y Alfonso Ruiz Vergara, del noveno semestre de Medicina Veterinaria y Zootecnia del segundo ciclo de 2006, de la Universidad de los Llanos, Colombia.

OCHOA, A. J. \& HERNANDEZ, A. G. Invasive mesothelioma of canine: cytology, clinical and pathology's findings. Int. J. Morphol., 26(1):103-112, 2008.

SUMMARY: This report describes the gross, microscopic features of an invasive epithelioid malignant mesothelioma and biphasic (mixed) malignant mesothelioma in an 8 -year-old male Pit -Bull, arrives to the Veterinary Clinic of the School of Veterinary Medicine and Zootecnia of the Faculty of Agricultural Sciences and Natural Resources of the Universidad de los Llanos, whose consultation reason was a increased of the size of abdomen, ascites, anorexia, weight lost, depression, breathing difficulty, vomit, according to the report of the owner, the animal had received treatment for the renal fail which occurred some months ago. The tumor involved the pericardium with two ulceratived neoplastic masses, pleura, mediastinum, and peritoneum with numerous, multiple foci, white neoplastic masses scattered through the peritoneum, and serous surfaces of the organs of the abdominal cavity as the right kidney, pancreas, and equality two bilobed masses with red color of $1 \times 1,5 \mathrm{~cm}$ in the subcutaneous tissue of the inguinal region by direct invaded through the peritoneum, implantation and direct invasion of the subjacent tissue. By histopathology was diagnosed a invasive epithelioid malignant mesothelioma and biphasic (mixed) malignant mesothelioma, with metastasis to kidney and pancreas, the neoplastic cells with frequent mitotic figures and binucleation that infiltrated submesothelial tissues. In the hemogram realized before the necropsy,we found blastic blood cell frotis and naked shared gross with a mielomonocitic leukaemya.

KEY WORDS: Canine; Mesothelioma; Mielomonocitic leukaemya.

\section{REFERENCIAS BIBLIOGRÁFICAS}

Abbas, A.; Peter, H. \& Wunsch. Epithelioid and sarcomatoid malignant pleural mesothelioma in endoscopio gastric biopsies: A diagnostic pitfall, Pathology. Research and Practice, 202:617-22, 2006.

Aronsohn, M. \& Carpenter, J. Surgical treatment of idiopathic pericardial effusion in the dog: 25 cases (1978-1993). J. Am. Animal Hospital Association, 35:521-5,1999.

Bacci, B.; Morandi F.; De Meo M. \& Marcato P. Ten cases of Feline Mesothelioma: an Inmunohistochemical and ultraestructural study. J. Comparative Pathology, 134:347- 54, 2006.

Berg, R.; Wingfield, W. \& Hoopes P. Idiopatic hemorrhagic pericardial effusion in eight dogs. J. Am. Veterinary Medical Association, 185:988-92, 1984.

Bernard, F.; Thomas, C; Emile, J.; Hercus, T.; Cassinat, B.; Chomienne, C. \& Donadieu, J. Transient hematologic and clinical effect of E21R in a child with end-stage juvenile myelomonocytic leukemia. Blood, 99(7):2615-6, 2002.

Borrow, M.; Costan, A. \& Livorness, L. Chest, 64:641-6, 1973.

Dias Pereira, P.; Azevedo, M. \& Gartner, F. Case of malignant biphasic mesothelioma in a dog. Vet. Rec., 149:680-1, 2001.

Glickman, L.; Domanski, L.; Maguire, T.; Dubielzig, R. \& Churg, 
A. Mesothelioma in pet dogs associated with exposure of their owners to asbestos. Environ. Res., 32:305-13, 1983.

Efremidis, A.; Waxman J.; Chahinian, A. Association of lymphocytic neoplasia and mesothelioma. Cancer, 55(5):1056-9, 1985.

Harbinson, M. \& Godleski, J. Malignant mesothelioma in urban dogs. Vet. Pathology, 20:531-40, 1983.

Head, K.; Cullen, J.; Dubielzig, R.; Else, R.; Misdorp, W.; Patnaik, A.; Tateyama, S. \& Van Der Gaag, I. Histological classification of tumors of the alimentary system of domestic Animals. Armed Forces Institute of Pathology and the World Health Organization Collaborating Center for Worldwide Reference on Comparative Oncology, Washington, DC, Second Series. V. X, 2003.

Jones, T.; Hunt, R. \& King, N. Veterinary Pathology. $6^{\mathrm{a}}$ ed. Lippincott, Williams \& Wilkins, Baltimore, 1997. pp 1089.

Kannerstein, M. \& Churg, J. Mesothelioma in a man and experimental animals. Environ Health Perspect., 34:31-6, 1980.

Kim, J.; Choi; Yoon, H.; Kweon, O. \& Kim, D. Juvenile malignant Mesothelioma in a dog. J. Veterinary Medicine Science, 64 (3):269-71, 2002.

Kobayashi, Y.; Usuda, H.; Ochiai, K. \& Itakura, C. Malignant mesothelioma with metastases and mast cell leukaemia in a cat. J. Comp. Pathol., 111(4):453-8, 1994.

Lopez, A. The respiratory system. In: Thomson's Special Veterinary Pathology, ed. Schrefer J.; Duncan L. \& Merchand, T. $3^{\text {a }}$ ed. Mosby, St. Louis, 2001.

Lupu, A.; Colita, A. \& Olteanu, N. Association of mesothelioma with chronic myelogenous leukemia in blast crisis coincidence or interdependence?. Annals of Fundeni Hospital, 2(2):99104, 1997.

Machida, N.; Tanaka, R.; Takemura, N.; Fujii, Y.; Ueno, A. \& Mitsumori, K. Development of pericardial mesothelioma in golden retrievers with a long- term history of idiopathic haemorrhagic pericardial effusion. J. Comparative Pathology, 131:166 -75, 2004.

Meuten, D. Tumors in domestic Animals. $4^{\text {th }}$. ed Iowa State Press, 2002.

Morini, M.; Bettini, G.; Morandi, F.; Burdisso, R.; \& Marcato, P. Deciduoid peritoneal mesothelioma in a dog. Vet. Pathol., 43:198201, 2006.

Mutsaers, S. The mesothelial cell. Int. J. Biochem. Cell. Biol., 36:9 16, 2004.

Nowicki, M.; Ostalska-Nowicka, D.; Kondraciuk, B. \& Miskowiak, B. The significance of substance $\mathrm{P}$ in physiological and malignant haematopoiesis. J. Clin. Pathol., 60:749-55, 2007.
Parkash, V.; Vidwans \& Carter, D. Benign mesothelial cells in mediastinal lymph nodes. Am. J. Surgical Pathology, 23: 12649, 1999.

Peters, M.; Tenhundfeld, I.; Stephan, I. \& Hewicker, T. Embolized mesothelial cells within mediastinal lymph nodes of three dogs with idiopathic haemorrhagic pericardial effusion. J. Comp. Path., 128:107-12, 2002.

Reggeti, F.; Brisson, B.; Ruotsalo, K.; Southorn, E. \& Btenzle D. Invasive epithelial mesothelioma in a dog. Veterinary Pathology, 42:77-81, 2005.

Reiko, N.; Ryuzo, U. \& Seishi, K. Growth of human myeloid leukemias in the human marrow environment of SCID-hu Mice. Blood, 82(8):2536-6, 1993.

Suarez, D. \& Izquierdo, F. Embolization of mesothelial cells in lymphatics: the route to mesothelial inclusions in lymph nodes? Histophatology, 33:570-5, 1998.

Tarrant, M.;Stokol, T.; Blue, J. T.; McDonough, S. P. \& Farrell, P. Diagnosis of chronic myelogenous leukemia in a dog using morphologic, cytochemical, and flow cytometric techniques. Veterinary Clinical Pathology, 30(1):19-24, 2001.

Valli, E.; Jacobs, R.; Parodi, A.; Vernau, W. \& Moore, P. Histologycal Classification of Hematopoyetic Tumors of Domestic Animals. Second series, V. VIII. Armed Forces Institute of Pathology. American Registry of Pathology. Washington, D. C., 2002.

Wilson, D. \& Dungworth, D: Tumors of the respiratory tract. In: Tumors in Domestic Animals, ed Meuten D. J. $4^{\text {th }}$. ed.Iowa State Press, Ames, I. A, 2002.

Yamate, J.; Tomita, A.; Kuwamura, M.; Mitsunaga, F. \& Nakamura, S. Spontaneus peritoneal malignat mesothelioma in a geriatric Japanese macaque (Macaca fuscata). Exp. Anim 56 (2):155-9, 2007.

Dirección para correspondencia:

Prof. Julieta Esperanza Ochoa Amaya

Escuela de Medicina Veterinaria y Zootecnia

Facultad de Ciencias Agropecuarias y Recursos Naturales

Universidad de los Llanos

Villavicencio- Meta

COLOMBIA

E-mail: julietaeochoa@yahoo.es Julieta.ochoa@gmail.com

Recibido : 07-09-2007

Aceptado: 14-01-2008 